\title{
The risk of not taking risks
}

\section{Clarifying complexity}

\section{Playing safe}

Congratulations on tackling current public procurement culture in your recent editorial $(\operatorname{arq} 12 / 1$, p. 3). It is essential that the architectural academic community takes on these matters so often considered to be boring in normal architectural discourse. For it is probably the creative person's propensity to be easily bored that has handed so much decision making to those who will default to lowest cost and least risk over long term value and innovation, let alone anything to do with art.

Both Jack Pringle, my predecessor as RIBA President, and I have spent a great deal of our and our colleagues' time trying to persuade government to adopt procurement policies that would encourage the best design. We have had some success in getting accepted by the Treasury the principles of Smart PFI - a way of operating public private partnerships that increases contact between architects/co-designers and clients/users from the early stages of the project through to detail, which is widely agreed to be the most reliable condition for design excellence. This is in contrast to the prevalent PFI practice where the designers are buried deep in the contractor's supply chain, brought out when there is a bid to be won but put back in their box in the delivery phases of the project. The case for the long term value of good design is now widely accepted by the politicians but significantly changing procurement systems, for example the way in which the current massive school building programme is being commissioned, is proving to be difficult.

In the recent review of the system by the Partnership for Schools we argued for the client side to retain a design team and develop schemes in close consultation with the schools and local community for handing to the bidding consortia for developing and pricing. This would not only produce better design but greatly reduce bid costs. We found that initially the logic of our case was accepted. But later when the other stakeholders, and in particular contractors and project managers, were consulted such an approach was considered to open the public sector to too much risk. Ostensibly this position is buttressed by a number of myths such as how PFI promotes innovation (it may do in finance but certainly not in design), and how integration of design and construction requires that the architect and the design team be employed by the contractor. But the more dispiriting underlying attitude is that architects cannot be trusted with the public client's money and are not really team players.

That is a sorry position for a profession who by training and aptitude should be the best placed to take a wide and inclusive view of the whole process in the interest of the best long-term result - to be the process integrators. We can and should rail against the miserable blame shifting risk shedding culture that dominates public life but must also admit that the architect's current condition is largely self inflicted. It arises from the distance from commerce and labour that is rooted in the early nineteenth-century formation of the profession, and is nowhere more explicit than in architectural academia which forms the core attitudes of young architects. But just as the condition is self-inflicted so it can be cured: through a firm engagement with the commercial and practical circumstances in which designs are realised as buildings. This is an intellectual issue not simply a pragmatic one. Professional practice can teach skills but it is harder to retrofit attitudes. I hugely admire the ability of schools of architecture to teach students to think and imagine architecture. I just want them to address its full and true consequences.

SUNAND PRASAD London

Sunand Prasad is President, RIBA and Senior Partner, Penoyre E Prasad LLP.

\section{Time for review}

It is timely to highlight the culture of risk aversion in the procurement of public buildings. At a time when risk analysis in banking is under scrutiny for having overlooked the threat of the American sub prime mortgage crisis it seems appropriate to question whether there is a genuine understanding of risk in architecture and if it obscures rather than illuminates the desire for quality public buildings.

What are the risks involved in creating a quality public building? Cost and time can be easily assessed and the experience of the team displayed, but quality is more difficult to quantify. This presents a problem when completing and judging Prequalification Questionnaires for public tenders. While quality is hard to quantify it is perhaps less difficult to identify, provided the assessors have appropriate skills and training. In the planning system this function is fulfilled by Design and Conservation Officers, who come from a wide variety of backgrounds. In recent times there 


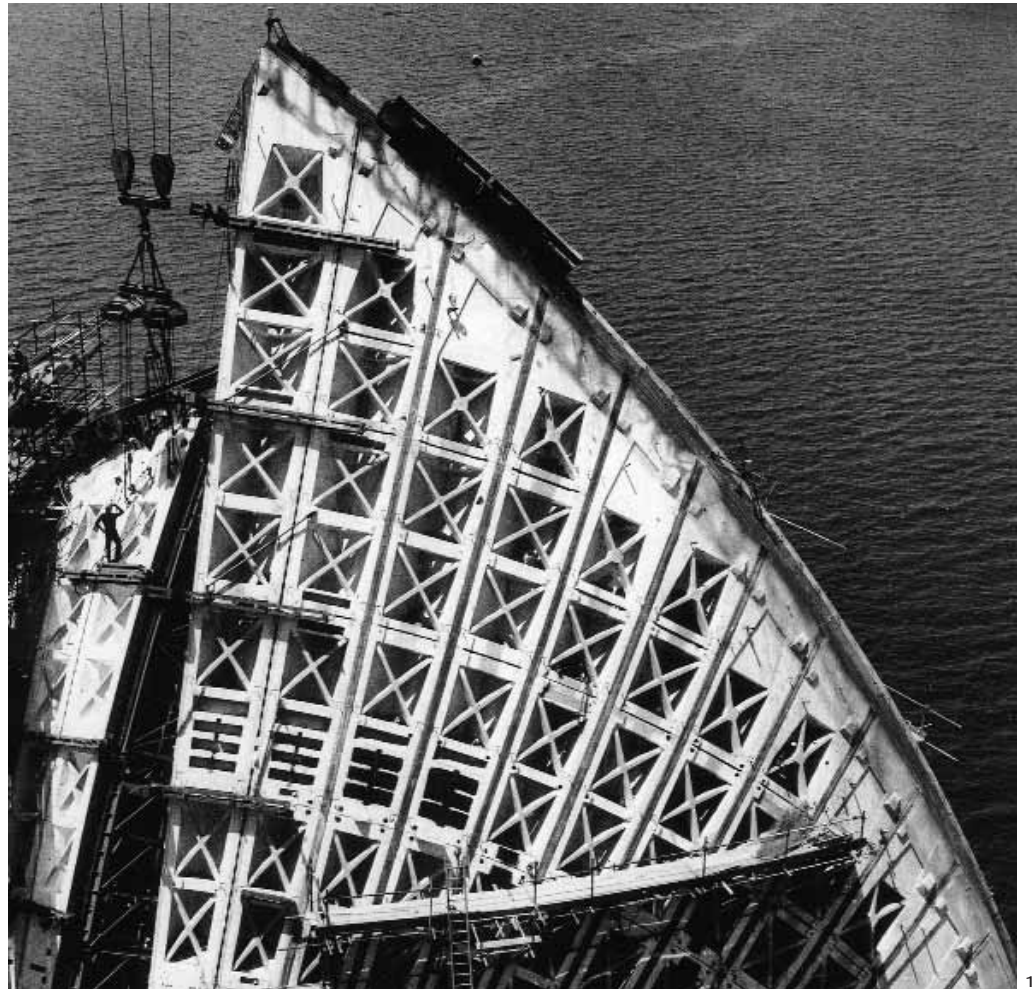

'Great buildings are like great evenings out - they often start slowly... are risky, go over budget and leave you immeasurably richer in other ways': Sydney Opera House under construction

has been a perceived lack of expertise in their ability to recognise good design. While an understanding of design is not the exclusive preserve of architects, the assessment of what represents quality is intrinsic to architectural education in the form of a crit or design review.

The RIBA's London Urbanism \& Planning Group has been helping to assist London Boroughs who feel they lack the appropriate skills in identifying good design and showing how to encourage it by aiding them in setting up local Design Review Panels consisting of a majority of architects. These are more local versions of CABE's Design Review and take a variety of formats in scrutinising schemes by peer review. They attempt to give a mechanism for promoting high quality schemes, improving mediocre ones and for identifying poor schemes that should be redesigned or refused.

If design review panels can help improve the quality of planning decisions and encourage clients and architects to raise their expectations, perhaps a similar peer review mechanism should be in place at the commissioning of all public buildings. This could allow smaller, innovative practices to be short-listed for projects that currently they have no chance of competing for, let alone winning. The best design ideas should be the primary qualification for winning a public project wherever they come from and appropriate mechanisms should be in place to encourage this and then enable delivery, rather than putting deliverability first and design quality second.

The risk that good design quality is lost at delivery is less than the risk that we deliver successfully poor quality design. The real concern about demolishing buildings of merit, be they Pimlico School or Robin Hood Gardens, is that the buildings which replace them will almost certainly be of lower quality rather than higher, precisely because of the culture of procurement today. Surely the greatest risk of all is that we leave a generation of anodyne public buildings for our children to grow up in.

LUKE TOZER

London

Luke Tozer is a founding partner of Pitman Tozer Architects Limited.

\section{The rights of risk}

The management of risk is something architects and their clients are increasingly concerned with. I wonder if the aim is more often to eliminate risk than manage it, as the desire for a predictable outcome is more keenly sought than ever. risk aversion that pervades public
As a medium-sized practice of 15 we hope to become involved with school building programmes and other public buildings but there is a difficulty in securing a first commission. Risk management by public clients and their project managers means that architects must demonstrate a track-record in delivering public buildings of a similar size and type before being considered for a new project. I need not point out the Catch-22 in this approach and we have employed various creative ways to bend our experience to fit what is asked for in the inevitable Expression of Interest.

Our building stock is littered with historical examples of risky buildings, and many of them are excellent. It takes a certain courage in a client to allow risk to persist in the design process - however it is managed. At odds with a climate of reduced unknowns and devolved responsibility is a desire in good clients to pursue creativity, novelty and delight. Owen Luder commented that when one meets a new client and has doubts about them, one should thank them, write out a cheque for $£ 20,000$ and say goodbye. This remains as true as when it was written in the 1980 s in that uninspired clients cannot generally be fired up, however talented their architect is. Good clients support their architects (and other professionals) and realise that the creative process is unpredictable, even when constrained by all the requirements that seek to deliver predictable results. Buildings can be designed by committee, or by contractors, and many of them have the required floor area, number of rooms, good services, are fairly 'sustainable' and delivered on time and in budget. They tend to be forgettable.

Enlightened clients are usually good ones and in the unusually competitive world of commercial office development Derwent London have proved this with a long history of developing excellent buildings. This has recently been recognised by the RIBA who selected Derwent as client of the year for 2007. Great buildings are like great evenings out - they often start slowly with an uncertain programme, go on for some time, are risky, go over budget and leave you immeasurably richer in other ways.

BEN ADAMS London

Ben Adams is a founding partner of Nissen Adams Architects. 

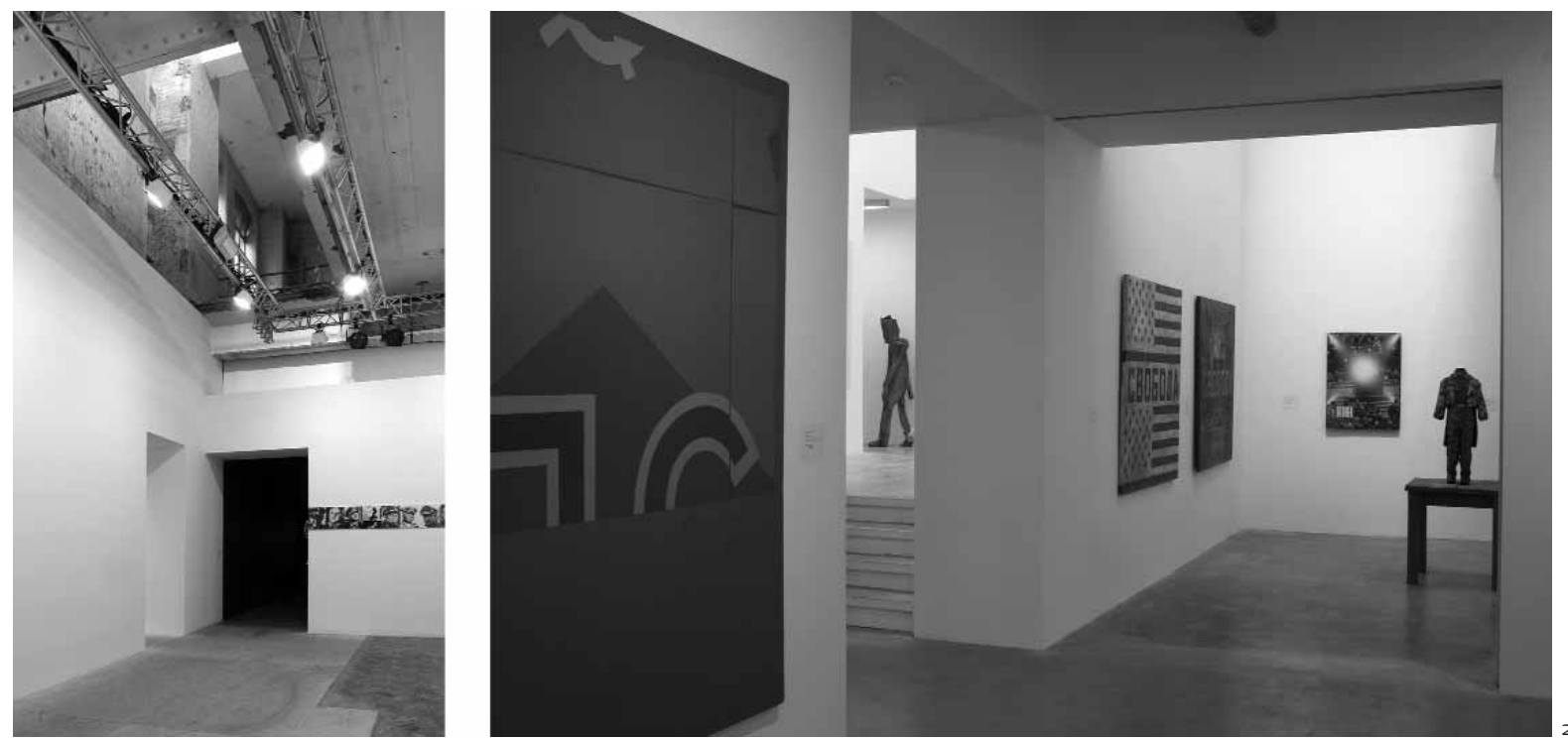

Changing conditions: the same space eighteen months apart demonstrates Nissen Adam's client, art auction house Phillips de Pury's, bold approach to risk and spatial change

\section{Simple complexities}

If the purpose of a polemic is to stimulate discussion, I am gratified by the extended length of Vincent Lacovara's response to my article (arq 12/1, pp. 4-6; 11/3+4, pp. 223-243). I need to point out that due to a rather short deadline the article as published was essentially the talk presented in Cardiff last June and was not as well argued as it could or should have been. While I am in complete accord with several of the points Mr. Lacovara advances, our opinions differ considerably on several others. I suspect these differences are continental, generational, or personal - or some combination of the three. Reading his letter I was reminded not only of my own youthful reading of Complexity and Contradiction in Architecture but also a number of articles I wrote years ago praising the wonders of diverse building, populism, and the American commercial vernacular environment in particular. Over the years, however, as maturity and/or old age has set in, my values have changed. While I have been provided neither the time nor space to address our differing attitudes in depth, let me single out several upon which to comment.

I do not know Mr. Lacovara's exact age, but in my own lifetime I have seen the world grow increasingly more complex. Comparisons of nineteenthcentury photos of virtually any city with those taken today would reveal increased complexity in form and information, not to mention increases in speed and compressions in time. In a recent issue of Visible Language I learned that even in 2003 there were five exabytes (explained as a billion gigabytes) of 'unique information' produced each year for every woman, man, and child on the planet. I seriously doubt if this number existed even fifty years ago as the figure had more than doubled since 2000 . No, I would still hold that today's world is far more complex and demanding than in past times and that the practice and products of architecture might acknowledge that change in some way.

More troubling is the assertion that I was arguing against all complexity, complexity as an abstract idea. In fact I argued specifically against a complexity in form without a concomitant complexity in experience - not against complexity in form per se.
Based on my own stance and values, the reasons for which I outlined in the text, I prefer simple things with complex experience rather than vice versa (admittedly I remain an only partially reconstructed Modernist). And when I spoke of gratuitous complexity, the typology I had in mind was primarily the art museum, the number of which has grown enormously in the United States. While I too support inclusion, I nonetheless question why an art museum should have virtually no external walls that can support a painting - I am thinking of the Denver Art Museum here. Clearly, other factors are determining the design of these buildings, many of them wilful, some of them market driven especially if we include the art and culture markets as part of the mix.

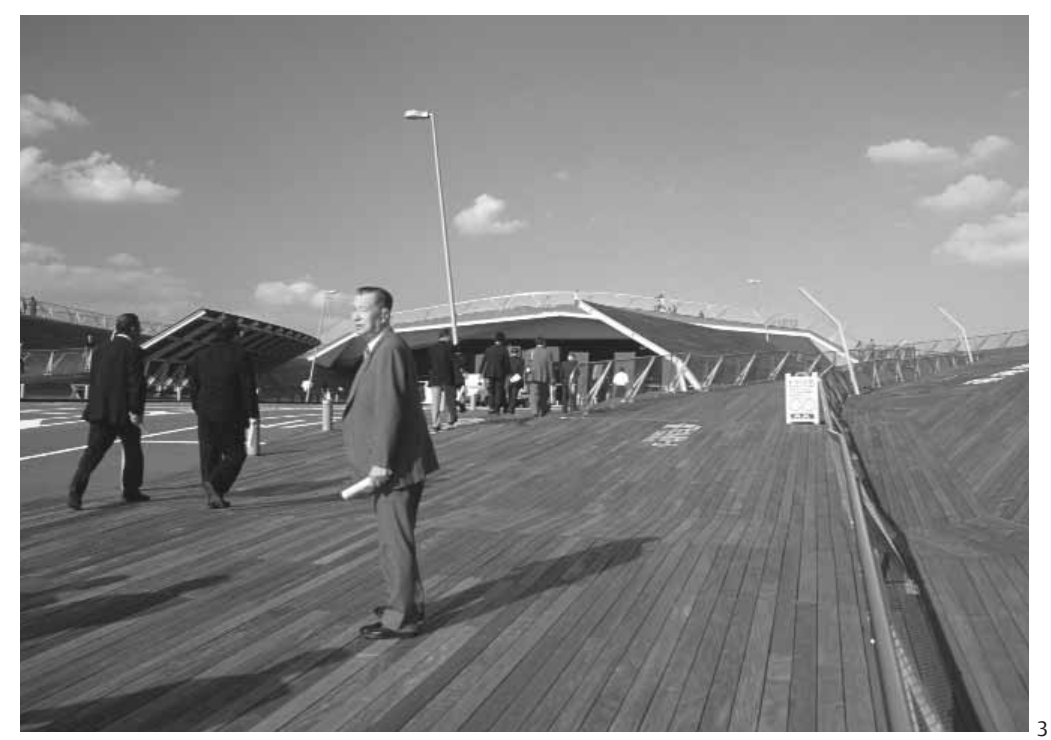

'Complex simplicities', Foreign Office Architects, International Passenger Terminal, Yokohama, Japan, 2002 


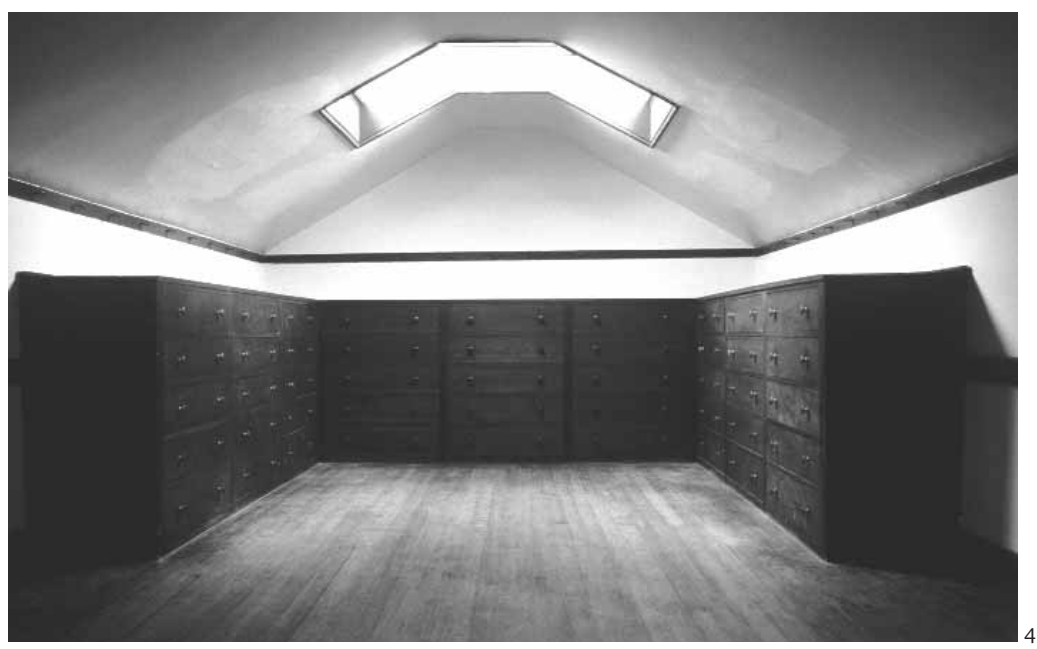

'Simple complexities', Centre family dwelling house, Pleasant Hill Shaker Village, Kentucky, 1834

Bridges are another matter. Loose fit works well for many buildings but is probably less germane to most bridge designs, unless they are on the order of the Ponte Vecchio. There is little question that a bridge can be a landscape and a symbol as well as a functional conveyance, but in the case of the bridge I mentioned its expression did seem rather overblown and more concerned with expression than engineering. Yes, the two can merge neatly in structures like the Eiffel Tower, but I don't believe the same thinking applies to a bridge traversing a narrow canal on essentially flat land.

Let me also make this clear. Like Mr. Lacovara I would not want a world of buildings by Mies or Ando or Aida. But neither would I want a world of the experientially deprived buildings that comprise the American Strip - their homogenised experience camouflaged under a thin blanket of seeming difference. Citing Kahn's call for bad buildings is all well and good, but do architects need to produce them? In my country 'bad buildings' sprout effortlessly, and although one may praise them in academic journals in the spirit of populism, their gifts are rarely worthy of aspiration or emulation. Architects do have a contribution to make beyond the world of the commercial vernacular - call me an elitist - and it would seem that providing moments of depth and tranquillity is one of them. Quiet is not the same as monastic retreat, as Mr. Lacovara implies, but a way of engaging in life, even urban life, in a more thoughtful and possibly fulfilling manner. For our important structures, if admittedly not for all of them, I still would seek simple complexities rather than complex simplicities.

MARC TREIB California

Marc Treib is Professor Emeritus of Architecture at the University of California, Berkeley.

\section{Illustration credits}

arq gratefully acknowledges: John Garth/Max Dupain, 1 Nissen Adams Architects, 2 Marc Treib, 3,4

Letters for publication should be sent to:

Richard Weston

arq

The Welsh School of Architecture Cardiff University

Bute Building

King Edward VII Avenue

Cardiff CF10 3 NB, UK

$\mathrm{T}:+44$ (29) 20874431

F: +44(29) 20874926

E:WestonR1@cardiff.ac.uk

The Editor reserves the right to shorten letters 